\title{
CLIMATOLOGIA SINÓTICA DE EVENTOS DE ONDAS DE FRIO SOBRE A REGIÃO SUL DE MINAS GERAIS
}

\author{
REBOITA, Michelle Simões - reboita@unifei.edu.br \\ Universidade Federal de Itajubá - Unifei \\ ESCOBAR, Gustavo - gustavo.escobar@cptec.inpe.br \\ Instituto de Pesquisas Espaciais - INPE \\ LOPES, Vitor Silva - slvitor@hotmail.com \\ Universidade Federal de Itajubá - Unifei
}

\begin{abstract}
RESUMO: Nesse estudo foram identificados os eventos de ondas de frio na Região Sul de Minas Gerais (RSMG) entre maio a setembro do período de 1965 a 2014 e caracterizados os padrões sinóticos associados com tais eventos. A média anual de ocorrência de ondas de frio é de 1,8 eventos, mas há grande variabilidade anual. Por exemplo, enquanto em 1968 foram registradas 8 ondas de frio na RSMG em 2014 não ocorreu nenhum evento. Os padrões sinóticos associados às ondas de frio foram caracterizados tanto em superfície, usando dados de pressão ao nível médio do mar, quanto em $500 \mathrm{hPa}$, com dados de altura geopotencial. Para isso, empregou-se a técnica de Padrões de Sequências Principais (PSPs) considerando o período desde dois dias antes do evento até o dia da ocorrência das ondas de frio. Em superfície, foram identificados 6 PSPs de ondas de frio, sendo 4 relacionados a processos advectivos e 2 a processos radiativos. Já em $500 \mathrm{hPa}$, foram encontrados 3 PSPs devido à menor variabilidade dos dados. Em superfície, o PSP que explica a maior variabilidade dos dados é o associado com um anticiclone entre o Pacífico e o sul da América do Sul e um ciclone no oceano Atlântico. Esses sistemas estão baroclinicamente acoplados com os em $500 \mathrm{hPa}$.
\end{abstract}

PALAVRAS-CHAVE: ondas de frio, análise de componentes principais, Região Sul de Minas Gerais

CLIMATOLOGY SYNOPTIC EVENT IN COLD WAVES IN SOUTH OF MINAS GERAIS

ABSTRACT: In this study, we identified the cold waves events over the southern of Minas Gerais (SMG) state, between the months of May-September over the years from 1965 to 2014. Moreover, the synoptic patterns associated with these events were described. The annual average of cold waves occurrence is 1.8 events, but there is a large annual variability. For example, while in 1968 occurred 8 cold waves in SMG, in 2014 there was none event registered. The synoptic patterns associated with cold waves were described as in surface, using mean sea level pressure data, as at $500 \mathrm{hPa}$, with geopotential height data. Therefore, we employed Principal Sequence Pattern Analysis (PSP), considering the period from two days before the event until the day of cold waves occurrence. On the surface, there are 6 PSP with 4 associated with advective process and 2 with radiative process. At $500 \mathrm{hPa}$, we found only $3 \mathrm{PSP}$ due to the lower data variability. On the surface, the PSP that explains the greater data variability is associated with an anticyclone between the Pacific and southern South America and a cyclone in the South Atlantic Ocean. These systems are baroclinicaly coupled with those at $500 \mathrm{hPa}$ level.

KEYWORDS: cold waves, principal component analysis, southern of Minas Gerais state 


\section{INTRODUÇÃO}

As ondas de frio são caracterizadas por sequências de dias em que a temperatura do ar torna-se menor do que um determinado limiar podendo causar danos à sociedade como, por exemplo, aumento de casos de doenças respiratórias, prejuízos à agricultura etc.

No centro-sul do Brasil, incluindo a Região Sul de Minas Gerais (RSMG), as ondas de frio são frequentes durante os meses de maio a setembro (HAMILTON e TARIFA, 1978; FORTUNE e KOUSKY, 1983; MARENGO et al., 1997; VERA e VIGLIAROLO, 2000; LUPO et al., 2001; SATYAMURTY et al., 2002; ESCOBAR, 2007) e os aspectos sinóticos associados a esses eventos têm sido descritos em alguns estudos. Hamilton e Tarifa (1978), ao estudarem uma forte incursão de ar frio nos setores subtropical e tropical da América do Sul (AS) em julho de 1972, verificaram a presença de um ciclone na costa do Uruguai e um anticiclone no noroeste da Argentina. A canalização de ar frio gerada pela circulação desses dois sistemas permitiu que a frente fria chegasse até $10^{\circ} \mathrm{S}$ sobre o Brasil. No Paraná e arredores, o ar frio propiciou a ocorrência de geadas. Os aspectos sinóticos descritos por Hamilton e Tarifa (1978) também foram similares aos observados por Fortune e Kousky (1983) durante a ocorrência de duas geadas severas sobre o Brasil: uma em maio de 1979 e outra em julho de 1981. Por exemplo, no caso de maio de 1979, que foi um exemplo clássico de incursão de ar frio na AS, um intenso anticiclone em superfície estendendo-se por quase toda a costa do Chile e um ciclone próximo ao Uruguai contribuíram para a intensa advecção de ar frio de altas para mais baixas latitudes gerando uma frente fria. Com o deslocamento do anticiclone para o continente, ocorreram condições propícias para a geada sobre o sul e sudeste do Brasil, até $20^{\circ} \mathrm{S}$. Essas características também são similares às descritas por Marengo et al. (1997) no estudo de um evento extremo de incursão de ar frio em latitudes tropicais e equatoriais da AS ocorrido em junho de 1994 e que teve consequências negativas para a produção de café no sudeste do Brasil.

Com base na análise de imagens de satélite, Girardi (1983) concluiu que o principal indicador da ocorrência de geadas no sudeste do continente sulamericano é a presença de um centro de alta pressão em níveis baixos e médios da atmosfera na costa chilena, que foi denominado pelo autor de Poço dos Andes. Tal aspecto concorda com os estudos prévios que mencionam a existência do anticiclone quando da incursão de ar frio na AS. Com base em conhecimentos prévios e numa climatologia com 17 anos de dados, Garreaud (2000) propôs um modelo conceitual de incursão de ar frio no sudeste da AS que, consequentemente, é favorável à ocorrência de ondas de frio. No estágio pré-incursão de ar frio há um extenso anticiclone na costa do Chile que começa a adentrar o continente pela região da Patagônia; no oceano Atlântico há uma baixa pressão nas latitudes do Uruguai ou, ligeiramente, mais altas, e conectada a ela há uma frente fria que atinge o sul da Argentina. No dia da incursão de ar frio cerca de metade do anticiclone já se encontra sobre o continente atingindo latitudes do Uruguai, enquanto o ciclone aparece deslocado para sudeste em relação ao dia anterior e a frente fria, para norte, chegando ao Rio Grande do 
Sul. Um dia após, o anticiclone domina todo o sul e sudeste da AS, o ciclone no oceano apresenta pouco deslocamento em relação ao dia anterior e a frente fria atinge a região norte do Brasil, originando um evento de friagem. É importante mencionar, que o processo descrito não é o único responsável por ocorrência de ondas de frio na AS, por exemplo, a estacionariedade do Anticiclone Subtropical do Atlântico Sul sobre o sudeste do Brasil, pode favorecer o resfriamento radiativo e proporcionar ondas de frio (ESCOBAR, 2007).

Pezza e Ambrizzi (2005) compilaram a ocorrência das ondas de frio mais intensas que atingiram o Brasil entre 1898 a 2003. Para tanto, foram utilizados dados de temperaturas mínimas extremas e de ocorrência de neve nas serras gaúcha, catarinense e da Mantiqueira. Além disso, os autores utilizaram um algoritmo de rastreamento de ciclones e anticiclones para avaliar a trajetória desses sistemas em casos de ondas de frio. Os resultados mostraram que os anticiclones se formam em latitudes médias no oceano Pacífico Leste, cruzam a Cordilheira dos Andes entre $35^{\circ}$ e $50^{\circ} \mathrm{S}$, deslocam-se para o Atlântico entre $23^{\circ}$ e $35^{\circ} \mathrm{S}$ e, por fim, agregam-se ao Anticiclone Subtropical do Atlântico Sul. Já os ciclones têm gênese na costa leste da AS e ciclólise nos arredores da Antártica.

Do ponto de vista climático, alguns trabalhos têm empregado a técnica de Análise de Componentes Principais (ACP), também chamada de Função Ortogonal Empírica (FOE), para identificar os padrões atmosféricos associados com as ondas de frio na AS. Por exemplo, Vera e Vigliarolo (2000), com a técnica de $F O E$, verificaram que quatro dias antes de um episódio de geada ocorrer sobre o sul do Brasil, a circulação atmosférica mostra um padrão de onda longa em níveis médios como precursor de geada no sul do Brasil. Essa onda é caracterizada por uma perturbação anticiclônica sobre o sudeste do oceano Pacífico e uma perturbação ciclônica (denotada como componente principal 1) sobre o sudeste da AS. Escobar (2007) estudou os padrões sinóticos associados às ondas de frio ocorridas na cidade de São Paulo nos meses de maio a setembro entre 1960 a 2002. Para tanto, foi utilizada a técnica de Padrões de Sequências Principais (PSPs), que corresponde à ACP adaptada para identificar padrões em sequências de dias. Entre os resultados têm-se que os três primeiros PSPs da pressão ao nível médio do mar (PNMM) representam 70\% da variância total dos dados, enquanto que para a altura geopotencial em $500 \mathrm{hPa}$, representam 94,5\%. Com relação ao PSP1 da PNMM, tem-se o padrão clássico de incursão de ar frio descrito em outros estudos: o anticiclone na costa chilena que adentra o continente pelo sul da AS $\left(45^{\circ} \mathrm{S}\right)$ e desloca-se para menores latitudes, enquanto que no oceano Atlântico há uma baixa pressão a cerca de $50^{\circ} \mathrm{S}$ e $30^{\circ} \mathrm{W}$. Já o PSP1 da altura geopotencial em $500 \mathrm{hPa}$ indica a presença de uma crista sob a região de alta em superfície e um cavado que tem eixo inclinado no sentido noroeste-sudeste, com porção central do eixo sobre o sul do Brasil no dia da ocorrência de onda de frio em São Paulo. Com relação ao PSP2 da PNMM, há um centro de baixa pressão entre a costa sul-sudeste do Brasil cercado por um sistema de alta pressão no seu setor sul-oeste. Em $500 \mathrm{hPa}, 0$ PSP3 é que se relaciona com o PSP2 da superfície. Tal padrão em níveis médios mostra, sobre a região de alta pressão em superfície, uma crista que se estende para sudeste de um centro de baixa em níveis médios caracterizando um padrão de bloqueio atmosférico. Por fim, o PSP3 da PNMM apresenta um padrão 
relacionado com a passagem de frentes frias com trajetória predominantemente zonal, devido à presença de um intenso cavado em $500 \mathrm{hPa}$ orientado quase meridionalmente no sul do continente (PSP2 em níveis médios).

Com relação ao padrão sinótico do campo de altura geopotencial em 500 hPa, com a presença de uma crista entre o Pacífico Sudeste e o Chile e um cavado a leste desse sistema em episódios de ondas de frio no sudeste da AS, Sprenger et al. (2013) indicam que essa onda longa é maximizada pela influência de vorticidade potencial, o que é importante para a quebra da onda de Rossby. De fato, uma análise com 27 eventos de incursão de ar frio revelou que a quebra da onda entre a AS e o oeste do Atlântico Sul é uma importante componente da dinâmica das incursões de ar frio no Brasil.

Como são poucos os estudos que identificam as ondas de frio em diferentes regiões da AS, esse trabalho tem como objetivo detectar as ondas de frio ocorridas na RSMG entre maio a setembro de 1965 a 2014 e caracterizar os padrões sinóticos (em superfície e em $500 \mathrm{hPa}$ ) associados com esses eventos. A justificativa desse estudo está no fato de que a classificação sinótica pode contribuir na melhoria da previsibilidade das ondas de frio.

\section{METODOLOGIA}

\subsection{Dados}

Foram utilizados dados diários de temperatura mínima e máxima, do período de 01/01/1965 a 31/12/2014, medidos na estação meteorológica de Lavras $\left(21,75^{\circ} \mathrm{S}\right.$ e $\left.45^{\circ} \mathrm{W}\right)$ que faz parte da rede do Instituto Nacional de Meteorologia (INMET). Essa estação meteorológica foi selecionada para o estudo tanto pelo seu posicionamento (sul de Minas Gerais) quanto pela qualidade e disponibilidade dos dados. Com relação à qualidade dos dados, inicialmente selecionaram-se os meses de interesse para o estudo, maio a setembro, a fim de se realizar um teste para verificação de dados errôneos. Tal teste foi baseado na Variação Interquartil (Interquartile Range, IQR) e na criação de limiares de confiança. O IQR é simplesmente a diferença entre os quartis superior (Q75\%) e inferior (Q25\%) de uma série de dados (WILKS, 2006). Com o IQR foram criados limiares superiores e inferiores, $\operatorname{LIMIAR}=\mathrm{Q} 75 \% \pm 3 \mathrm{IQR}$, seguindo Sugahara et al. (2012). O passo seguinte foi verificar se algum dado das séries temporais de temperatura máxima e mínima excediam tais limiares. Ambas as séries temporais não apresentaram dados acima do limiar superior. Porém a série de temperatura mínima possuía 11 dados abaixo do limiar inferior, enquanto a de temperatura máxima, 17 dados. Como esses dados foram similares ao de estações meteorológicas da vizinhança de Lavras não foram considerados como errôneos. Devido à ausência de dados, os anos de 1967, 1979, 1980, 1981, 1985, 1986, 1987, 1990 e 1992 foram excluídos da análise. Assim, o estudo das ondas de frio na RSMG incluiu 41 anos no período de 1965 a 2014. 
Para a caracterização sinótica dos eventos de ondas de frio na RSMG foram usados dados de PNMM e altura geopotencial em $500 \mathrm{hPa}$, provenientes da reanálise R1 do National Center for Environmental Prediction/National Center for Atmospheric Research (KALNAY et al., 1996), no período de 1965 a 2014. A reanálise corresponde a dados observados (por diferentes métodos: estações meteorológicas, radiossondas, navios e aviões instrumentados etc.) e que são assimilados por modelos atmosféricos permitindo uma distribuição regular no tempo e no espaço. No caso da reanálise $\mathrm{R} 1$, os dados possuem resolução horizontal de 2,50 de latitude por 2,50 de longitude e resolução temporal de 6 horas. Para o presente estudo utilizou-se dados correspondentes às 12 UTC, em pontos de grade, das variáveis PNMM e altura geopotencial em $500 \mathrm{hPa}$ da reanálise $\mathrm{R} 1$ na área indicada na Figura 1 . Tal figura também apresenta a topografia da América do Sul.

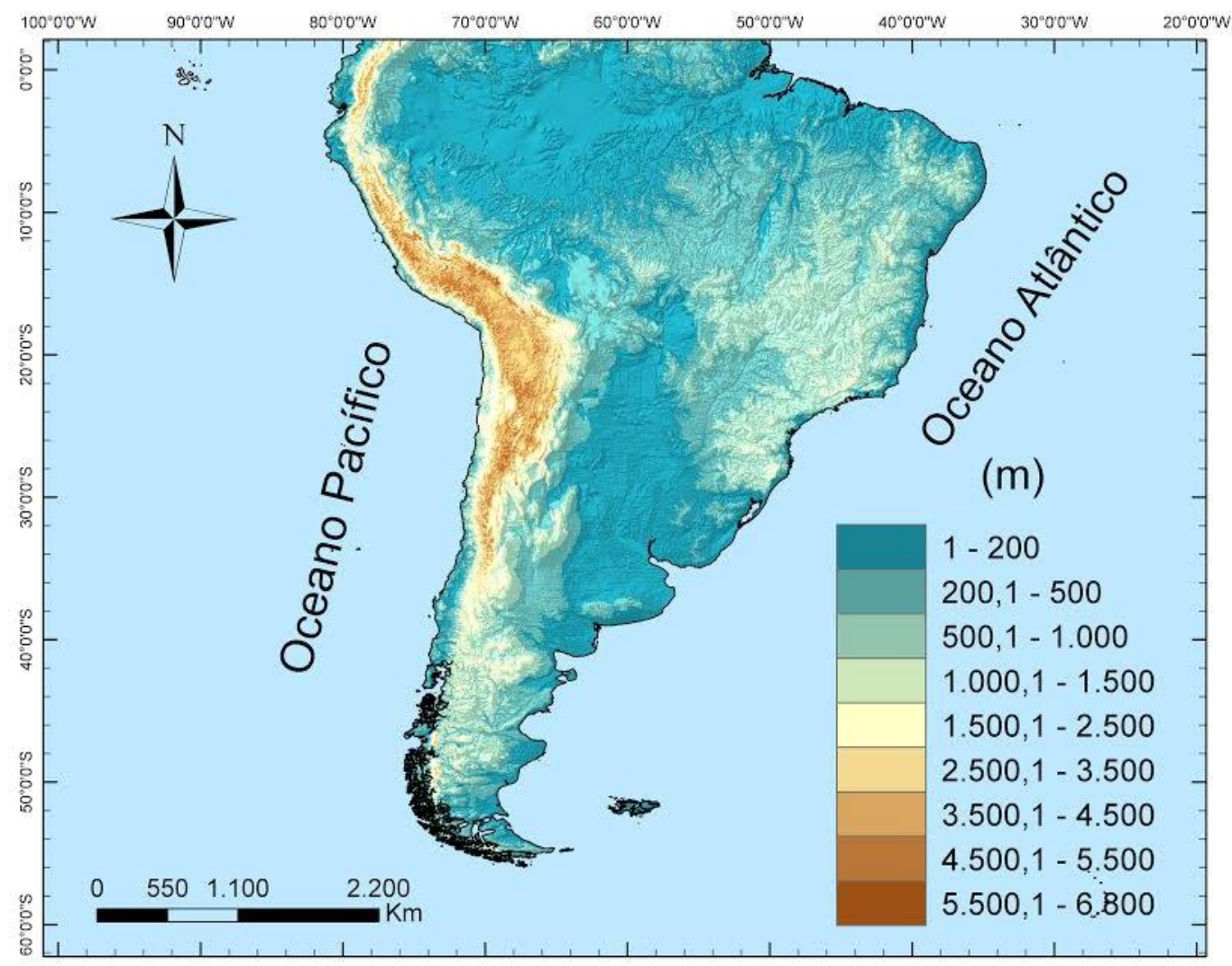

Figura 1 Área em que a reanálise R1 foi obtida para o estudo e topografia (metros) da América do Sul representada com base nos dados GTOPO do U.S. Geological Survey's Center for Earth Resources Observation and Science.

\subsection{Critérios para a Identificação de Ondas de Frio}

O critério para a identificação das ondas de frio na RSMG seguiu a metodologia de Nairn e Fawcett (2013) com uma pequena modificação. Na 
metodologia desses autores, uma onda de frio ocorre quando pelo menos em três dias consecutivos a temperatura média do ar ( $T_{M}$, equação 1$)$ é abaixo do percentil de $5 \%$ da série histórica.

$$
T_{M}=\left(T_{M A X}+T_{M I N}\right) / 2
$$

No presente estudo, restringiu-se o período para pelo menos 2 dias, já que as massas de ar frio que chegam na RSMG não conseguem atuar por vários dias consecutivos. O percentil de $5 \%$ calculado para o período de maio a setembro foi de $15^{\circ} \mathrm{C}$.

\subsection{Análise de Componentes Principais para a Identificação dos Padrões Sinóticos Associados às Ondas de Frio}

Com base nas datas de ocorrência das ondas de frio na RSMG foi realizada uma classificação sinótica dos padrões atmosféricos nos campos de PNMM e de altura geopotencial em $500 \mathrm{hPa}$ associados às ondas de frio. A classificação incluiu uma sequência de dias que foi formada pelos campos de circulação correspondentes aos dias -2, -1 e 0 (onde 0 corresponde ao primeiro dia da onda de frio na RSMG).

Os Padrões de Sequências Principais (PSPs) foram obtidos usando a aproximação de Compagnucci et al. (2001). Nesta aplicação as variáveis são sequências de padrões espaciais de PNMM e de altura geopotencial em $500 \mathrm{hPa}$ e a matriz de correlação representa a correlação entre sequências. Esta aproximação é considerada como uma extensão da tradicional $A C P$, com uma matriz de correlação em Modo-T (GREEN, 1978; RICHMAN, 1986), cujo objetivo é obter a evolução dos principais modos dominantes da circulação que permitam analisar a trajetória e o comportamento dos sistemas sinóticos sobre determinadas áreas. Após a aplicação de tal aproximação foi feita a rotação Varimax. A rotação das componentes principais tem como principal objetivo redistribuir a variância total dos dados utilizados com o intuito de facilitar o significado físico das componentes obtidas (RICHMAN, 1986). Para a determinação do número de componentes rotacionadas utilizou-se a regra do autovalor 1.0 (RICHMAN et al., 1992). Isto é, o número de componentes principais retidas para análise deve ser igual ao número de autovalores maior do que 1.

Para a determinação das sequências de situações meteorológicas altamente correlacionadas com os PSPs foram utilizadas as séries temporais de factor loadings (componentes de peso) que representam as correlações entre cada variável (situação meteorológica real) e cada componente principal (RICHMAN, 1986). A análise da série de factor loadings permite determinar a representatividade das componentes principais como situações sinóticas reais, onde os valores próximos a 1 representam sequências de situações meteorológicas similares às sequências das componentes principais obtidas (HARMAN, 1976; CATTEL, 1978). 


\section{RESULTADOS}

\subsection{Identificação das Ondas de Frio}

Nos 41 anos analisados foram identificadas 76 ondas de frio na RSMG, 0 que fornece uma média anual de 1,8 eventos e um desvio-padrão de 1,7. Portanto, nota-se que há uma grande variabilidade anual na ocorrência das ondas de frio. Isso também pode ser visualizado na Figura 2. Além disso, verifica-se que 1968 foi o ano com maior ocorrência de ondas de frio (8 casos), enquanto que não há ocorrência desse fenômeno em 1993, 1995, 2002, 2006, 2008, 2011 e 2014. Com relação a duração das ondas de frio, essa é em média de 3 dias.

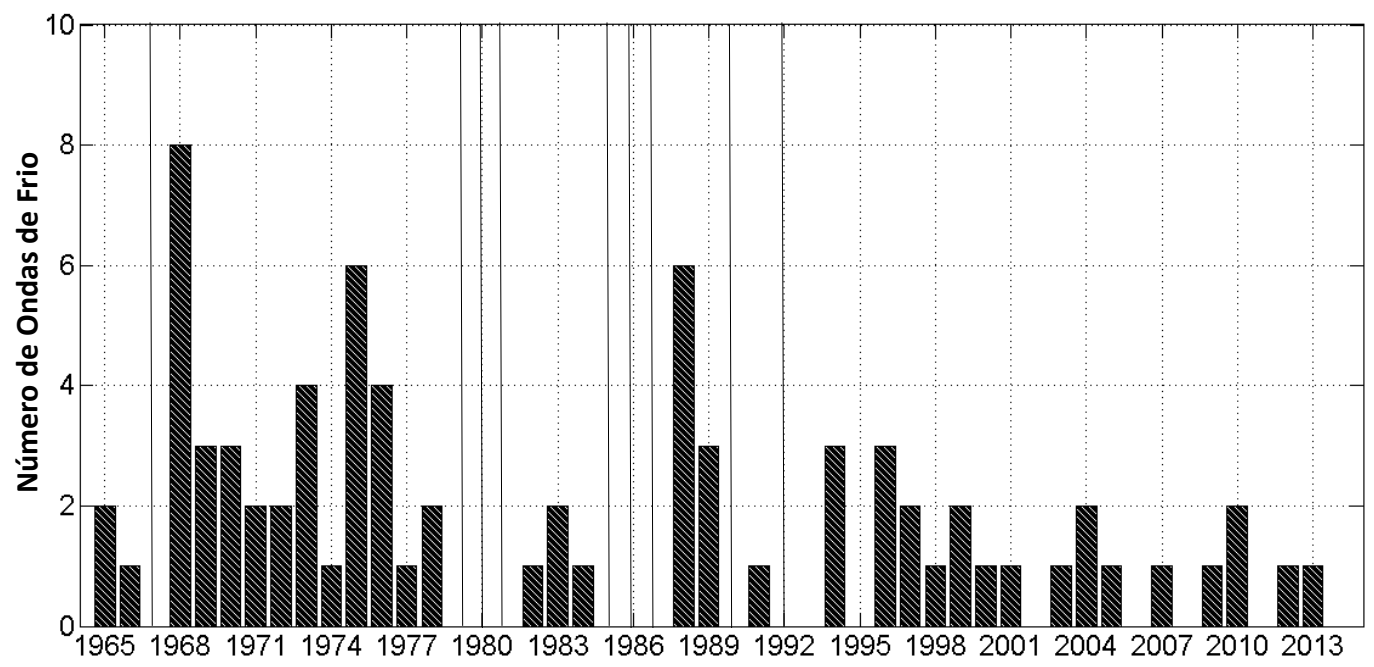

Figura 2 Ocorrência anual de ondas de frio na RSMG. As linhas pretas indicam os anos que não foram incluídos nas análises por falta de dados (1967, 1979, 1980, 1981, 1985, 1986, 1987, 1990 e 1992).

\subsection{Padrões Sinóticos Associados às Ondas de Frio}

A aplicação da ACP identificou seis PSPs em superfície e três PSPs em 500 hPa, que explicaram $81,7 \%$ e $93,7 \%$ da variância todal dos dados, respectivamente (Tabela 1 ). Em 500 hPa o número de PSPs é menor, uma vez que nesse nível a variável altura geopotencial é mais suavizada do que próximo à superfície e, portanto, apresenta menor variabilidade. Assim, os PSPs em superfície e $500 \mathrm{hPa}$ serão apresentados tanto separadamente quanto em conjunto. 
Tabela 1 Porcentagens da variância explicada e da variância acumulada por cada PSP de superfície (esquerda) e de 500 hPa (direita).

\begin{tabular}{c|c|c|c|c}
\hline \multirow{2}{*}{ PSPs } & \multicolumn{2}{|c|}{ PNMM } & \multicolumn{2}{c}{ Altura Geopotencial - 500 hPa } \\
\cline { 2 - 5 } & VAR (\%) & VAR ACUM (\%) & VAR (\%) & VAR ACUM (\%) \\
\hline 1 & 26,3 & 26,3 & 42,5 & 42,5 \\
\hline 2 & 23,4 & 49,7 & 40,4 & 82,9 \\
\hline 3 & 17,6 & 67,3 & 10,8 & 93,7 \\
\hline 4 & 7,0 & 74,3 & & \\
\hline 5 & 4,1 & 78,4 & & \\
\hline 6 & 3,3 & 81,7 & & \\
\hline
\end{tabular}

\subsubsection{Pressão ao Nível Médio do Mar}

O primeiro PSP (PSP1-Sup; Figura 3a-c), que explica 26,3\% da variância dos dados, revela que as ondas de frio na RSMG estão relacionadas a um padrão sinótico similar ao das típicas incursões de ar frio na AS (por exemplo, GIRARDI, 1983; GARREAUD, 2000; ESCOBAR, 2007). Isto é, no dia -2 (Figura 3a) há um anticiclone pós-frontal entre o oceano Pacífico e o sul da AS ( $45^{\circ} \mathrm{S}$ e $75^{\circ} \mathrm{W}$ ) e um ciclone afastado da costa no oceano Atlântico $\left(55^{\circ} \mathrm{S}\right.$ e $\left.30^{\circ} \mathrm{W}\right)$. Além desses sistemas, há um ramo frontal frio atuando sobre o sudeste e centro-oeste do Brasil associado a uma área de baixa pressão na costa sul-sudeste do país. No dia -1 (Figura 3b), o sistema frontal frio e o anticiclone estão localizados em latitudes mais baixas do que no dia anterior; agora a frente fria situa-se entre a RSMG e o sul do Amazonas. Já no dia 0 (Figura 3c), o anticiclone pós-frontal atua sobre toda a AS (exceto nas regiões norte e nordeste) o que influenciou a frente a se deslocar e se estacionar entre o sul da Bahia e o sul do Amazonas. Tais sistemas são responsáveis por forte advecção de ar frio fazendo com que as temperaturas declinem na RSMG. O caso real escolhido (correlação de 0,92) corresponde ao período de 20 a 22 de julho de 1996 (Figura 3d-f) e mostra claramente no dia 0 a atuação do anticiclone pós-frontal sobre a RSMG.

O segundo PSP (PSP2-Sup, Figura 4a-c), que explica 23,4\% da variância dos dados, está associado a um anticiclone migratório pós-frontal que se desloca lentamente entre os dias -2 e 0 e adquire características subtropicais durante 0 dia do evento (dia 0). No dia -2 (Figura 4a), o anticiclone pós-frontal está centrado em $40^{\circ} \mathrm{S}$ e $55^{\circ} \mathrm{W}$ e a nordeste deste sistema de alta pressão há um sistema frontal frio sobre o norte do Rio de Janeiro, cruzando a RSMG e se estendendo de maneira estacionária até o sul de Mato Grosso. No dia -1 (Figura 4b), a frente fria encontra-se sobre o Espírito Santo e o anticiclone pós-frontal já atua sobre a RSMG, mas aumenta sua área de atuação no dia 0 (Figura 4c), quando adquire características do Anticiclone Subtropical do Atlântico Sul (ASAS). O caso real correlacionado em 0,84 com o PSP2-Sup (Figura 4d-f) se refere ao período de 06 a 08 de julho de 2005. Nesse é evidente que 0 anticiclone pós-frontal adquire características subtropicais à medida que se desloca lentamente para leste. 
É importante destacar que enquanto no PSP1-Sup (Figura 3) a redução das temperaturas na RSMG ocorre por efeito de advecção de ar frio (o que pode ser inferido dos PSPs), no PSP2-Sup (Figura 4), o resfriamento se dá por perda radiativa noturna. E neste último caso, os declínios mais significativos ocorrem na temperatura mínima.

O terceiro PSP (PSP3-Sup, Figura 5a-c), que explica 17,6\% da variância dos dados, está relacionado com o campo médio climatológico de inverno da AS e adjacências. Nesse, há um cavado que se estende do sul da AS até o norte da Patagônia Argentina, onde se junta a uma outra área de baixa pressão posicionada a sotavento dos Andes que está relacionada com a presença da Baixa Térmica do Noroeste da Argentina (BNOA; ESCOBAR e SELUCHI, 2012). No dia 0 (Figura $5 \mathrm{c}$ ) é possível identificar a BNOA entre o centro-norte da Argentina, oeste do Paraguai e o sul da Bolívia. Outra característica típica do inverno é a atuação de parte do setor oeste-noroeste do ASAS sobre as regiões sul e sudeste do Brasil, já que nessa época do ano esse sistema encontra-se mais a oeste do que no verão (REBOITA et al., 2012). A semi-estacionariedade do ASAS contribui para o aumento da perda radiativa noturna ao longo dos dias, o que causa ondas de frio na RSMG devido, principalmente, a queda brusca da temperatura mínima. O exemplo de um caso real do PSP3-Sup é mostrado na Figura 5d-f. Esse caso ocorreu entre os dias 29 a 31 de julho de 1988 e tem correlação de 0,92 com o PSP3-Sup. É possível observar, ao longo de toda a sequência, um cavado frontal deslocando-se do sul da Argentina para o oceano Atlântico. No dia -2 (Figura 5d) esse sistema encontra-se no sul da Provínica de Buenos Aires (Argentina) enquanto que no dia 0 a frente fria se estende até o Uruguai (Figura 5f). Ao longo desta sequência também é possível observar um pulso anticiclônico que se desprende do Anticiclone Subtropical do Pacífico Sul (ASPS) em direção ao continente acompanhando o deslocamente da frente. 0 avanço do sistema frontal faz com que o ASAS se desloque ligeiramente para nordeste em direção à RSMG, favorecendo a perda noturna de radiação.

O quarto PSP (PSP4-Sup, Figura 6a-c), que explica 7,0\% da variância dos dados, também está associado com o avanço de uma intensa frente fria que chega à RSMG. Neste caso, nota-se que o sistema frontal está associado a um intenso ciclone extratropical que no dia -2 se posiciona a cerca de $44^{\circ} \mathrm{S}$ e $50^{\circ} \mathrm{W}$ e no dia 0 chega até $40^{\circ} \mathrm{S}$ e $42^{\circ} \mathrm{W}$. Na retaguarda de tal ciclone é possível observar o anticiclone migratório que atravessa os Andes em $\sim 38^{\circ} \mathrm{S}$ e no dia 0 (Figura 6c) se localiza entre o norte da Argentina, oeste do Paraguai e o sul da Bolívia. Ambos os sistemas (ciclone e anticiclone) configuram um intenso gradiente de pressão entre o leste da Argentina e a porção leste das regiões sul e sudeste do Brasil. Desta maneira é possível deduzir a ocorrência de significativa advecção fria de temperatura sobre a RSMG durante o dia do evento (dia 0). O caso real do PSP4-Sup, mostrado na Figura 6d-f, ocorreu entre os dias 17 a 19 de junho de 1973 e tem correlação de 0,83 com o PSP4-Sup. Tal sequência mostra o avanço da frente fria com trajetória para nordeste, com um intenso ciclone extratropical no oceano Atlântico Sul e um anticiclone migratório pós-frontal avançando até aproximadamente o paralelo $20^{\circ} \mathrm{S}$ no dia 0 . 
A diferença entre o PSP4-Sup (Figura 6) e o PSP1-Sup (Figura 3) está relacionada com o comprimento da onda meteorológica. O PSP1-Sup mostra um sistema mais lento e de comprimento de onda maior em relação ao PSP4-Sup. Neste último, também é possível observar que o anticiclone migratório pósfrontal cruza os Andes mais ao norte em relação ao PSP1-Sup e em, consequência, desloca-se até latitudes mais baixas.

O quinto PSP (PSP5-Sup, Figura 7a-c), que explica 4,1\% da variância dos dados, revela um processo ciclogenético entre a costa sul-sudeste do Brasil. No dia -2 (Figura 7a) há um cavado invertido com eixo sobre o Estado do Rio Grande do Sul. Ao sul desse sistema, acerca das Ilhas Malvinas, há um intenso e abrangente anticiclone. Ao longo da sequência, evidencia-se o processo de formação da onda frontal (ciclogênese), cujo ramo frio se localiza no dia 0 (Figura 7c) entre os estados do Rio de Janeiro e Espírito Santo e atravessa o centro-sul de Minas Gerais. Simultaneamente, durante todo esse processo, o anticiclone migratório pós-frontal se desloca lentamente para leste. O caso real altamente correlacionado $(0,80)$ com o PSP5-Sup (Figura $7 d$-f) corresponde aos dias 21 a 23 de julho de 1973 e mostra claramente o processo de formação da onda frontal. No dia 0 (Figura 7f), o ciclone extratropical associado com a frente fria se posiciona no Atlântico, a sudeste do Rio de Janeiro. Através desta configuração bárica, é possível inferir a ocorrência de advecção fria sobre a RSMG dando início à onda de frio. Um padrão sinótico similar foi encontrado por Escobar (2007) quando realizou uma classificação sinótica associada com a ocorrência de ondas de frio na cidade de São Paulo.

O sexto PSP (PSP6-Sup, Figura 8a-c), que explica 3,3\% da variância dos dados, também está associado com um processo ciclogenético sobre o oceano Atlântico Sudoeste, a leste das regiões sul e sudeste do Brasil. A principal diferença desse PSP em relação ao PSP5-Sup é devida à configuração espacial da região ciclogenética. No PSP6-Sup há uma ampla área de baixa pressão com dois mínimos relativos, um localizado a leste do Rio Grande do Sul e o outro na altura do sul do Rio de Janeiro. Por outro lado, a alta localizada a sul desse sistema é menos intensa e abrangente do que no PSP5-Sup. Considerando novamente o PSP6-Sup, entre os dias -1 e 0 (Figura 8b-c), os dois mínimos relativos de pressão se juntam caracterizando apenas um único ciclone cujo ramo frio atravessa o sul da Bahia. O caso real altamente correlacionado $(0,91)$ com o PSP6-Sup corresponde aos dias 06 a 08 de junho de 1997 (Figura 8d-f). Esta sequência permite identificar os dois mínimos relativos de pressão durante o dia -2 , que ao longo do período se acoplam configurando apenas um único sistema. Também é possível observar a penetração do ar frio até latitudes baixas, mediante a trajetória meridional do anticiclone migratório pós-frontal.

Em síntese, nos PSPs 1, 4, 5 e 6 as ondas de frio na RSMG ocorrem associadas à advecção de ar frio, enquanto que nos PSPs 2 e 3 por resfriamento induzido por perda noturna de radiação. 

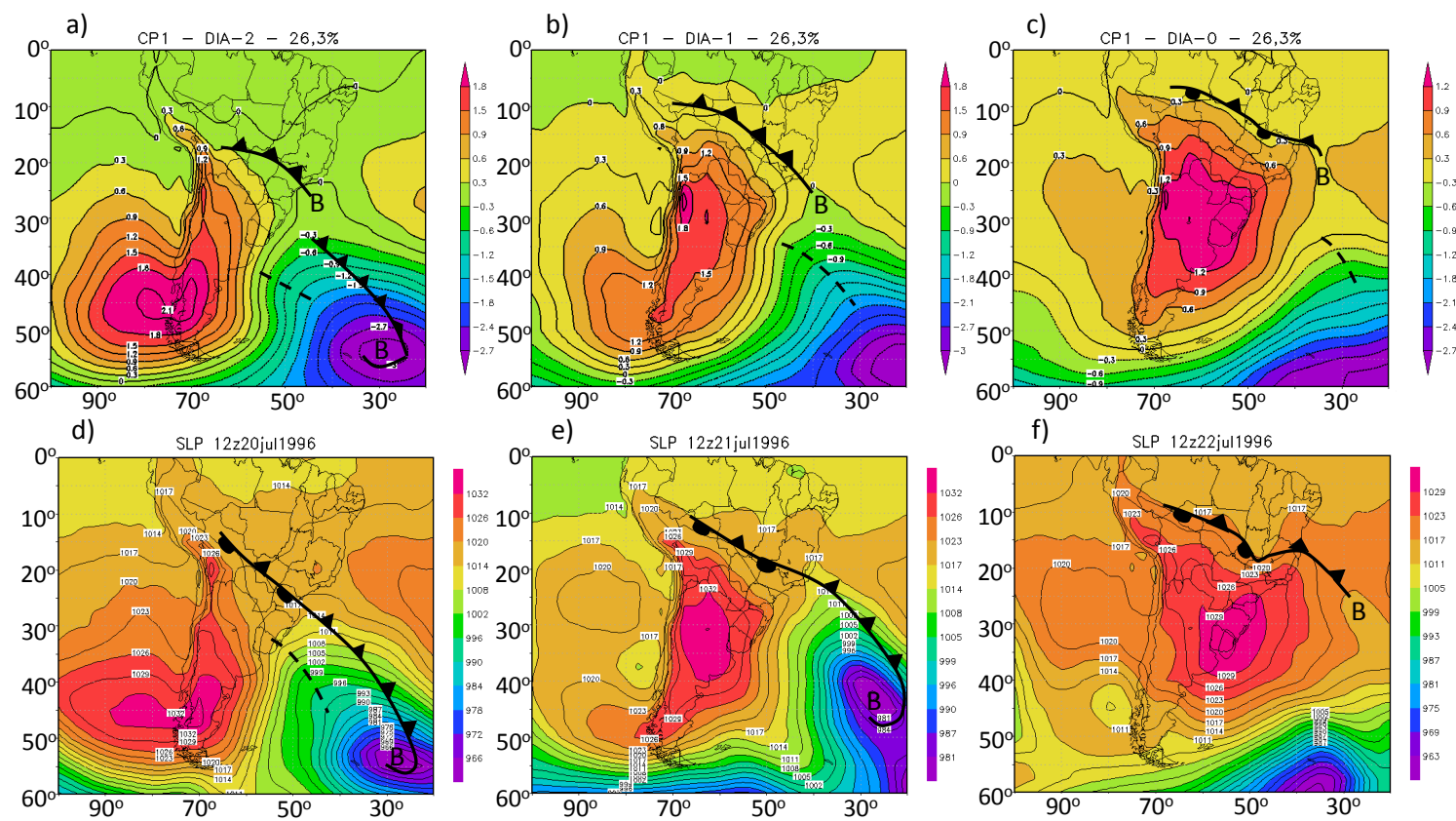

Figura 3 (a-c) Primeira Sequência de Componentes Principais (PSP1-Sup) para a PNMM desde o dia -2 ao dia 0 e (d-f) caso real de onda de frio ocorrido entre 20 e 22 de julho de 1996 (PNMM em hPa). As linhas tracejadas indicam a posição de cavados; as linhas com triângulos, frentes frias; as linhas com semicírculos, frentes quentes e as linhas com alternância de triângulos e semicírculos, frentes estacionárias.

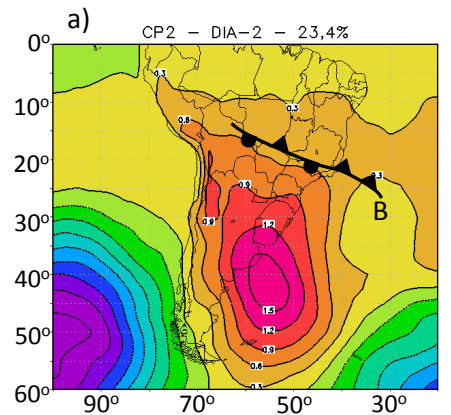

d)

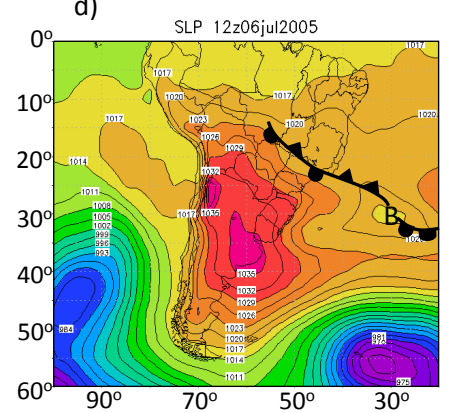

b)

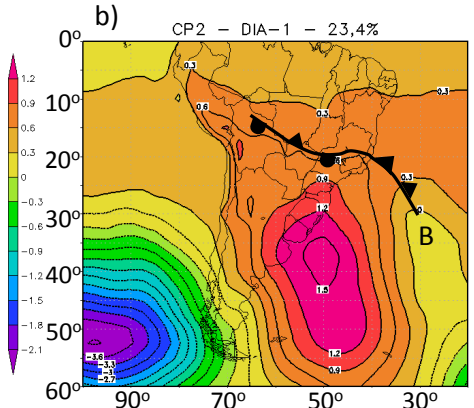

e)
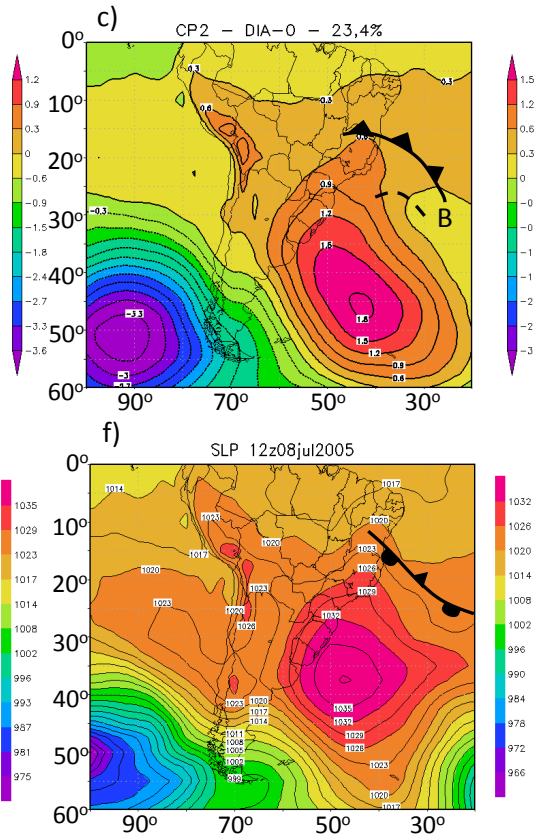

Figura 4 Similar à Figura 3, mas para o PSP2-Sup. O caso real de onda de frio se refere ao período de 06 a 08 de julho de 2005. 

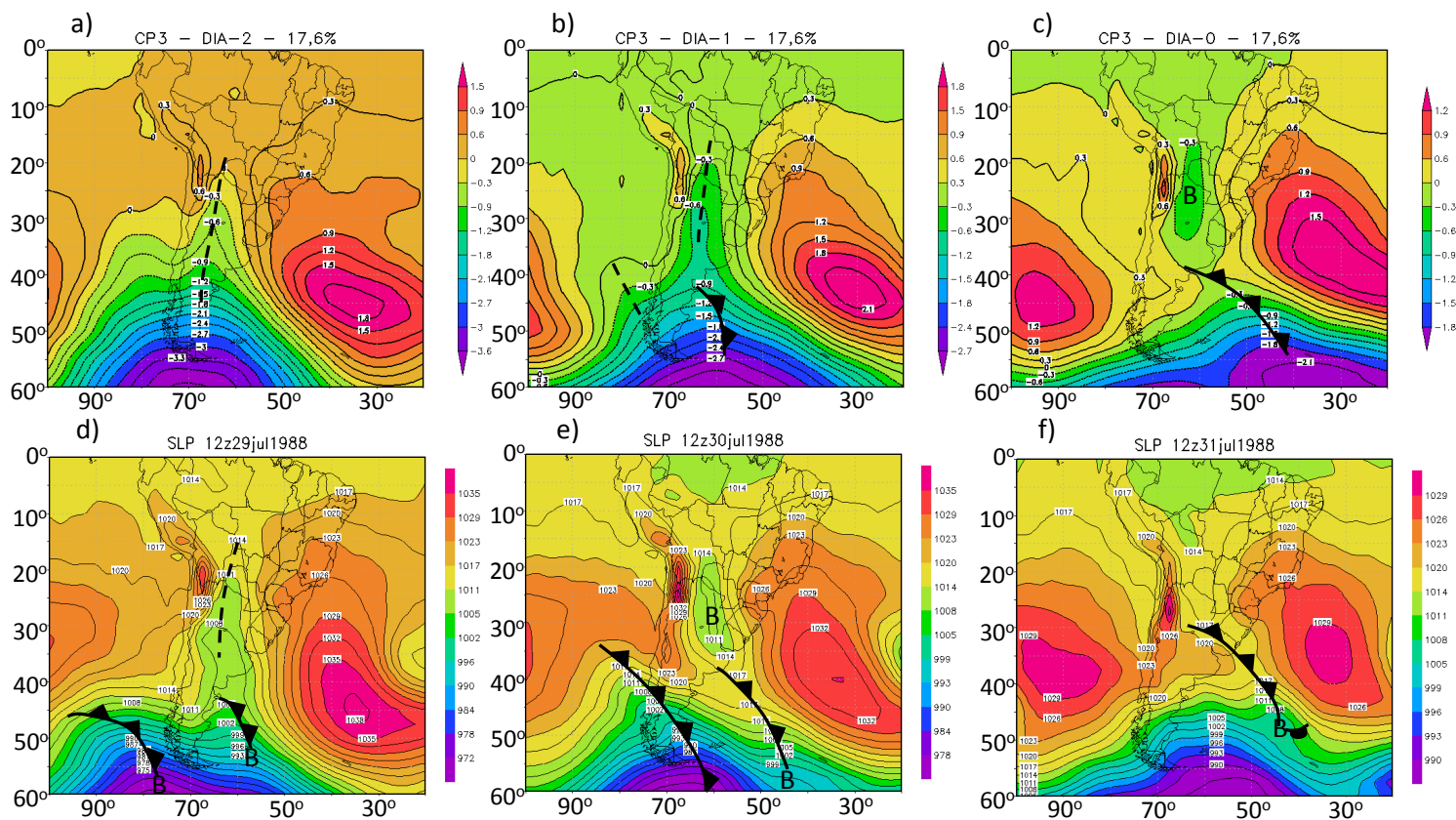

Figura 5 Similar à Figura 3, mas para o PSP3-Sup. O caso real de onda de frio se refere ao período de 29 a 31 de julho de 1988.
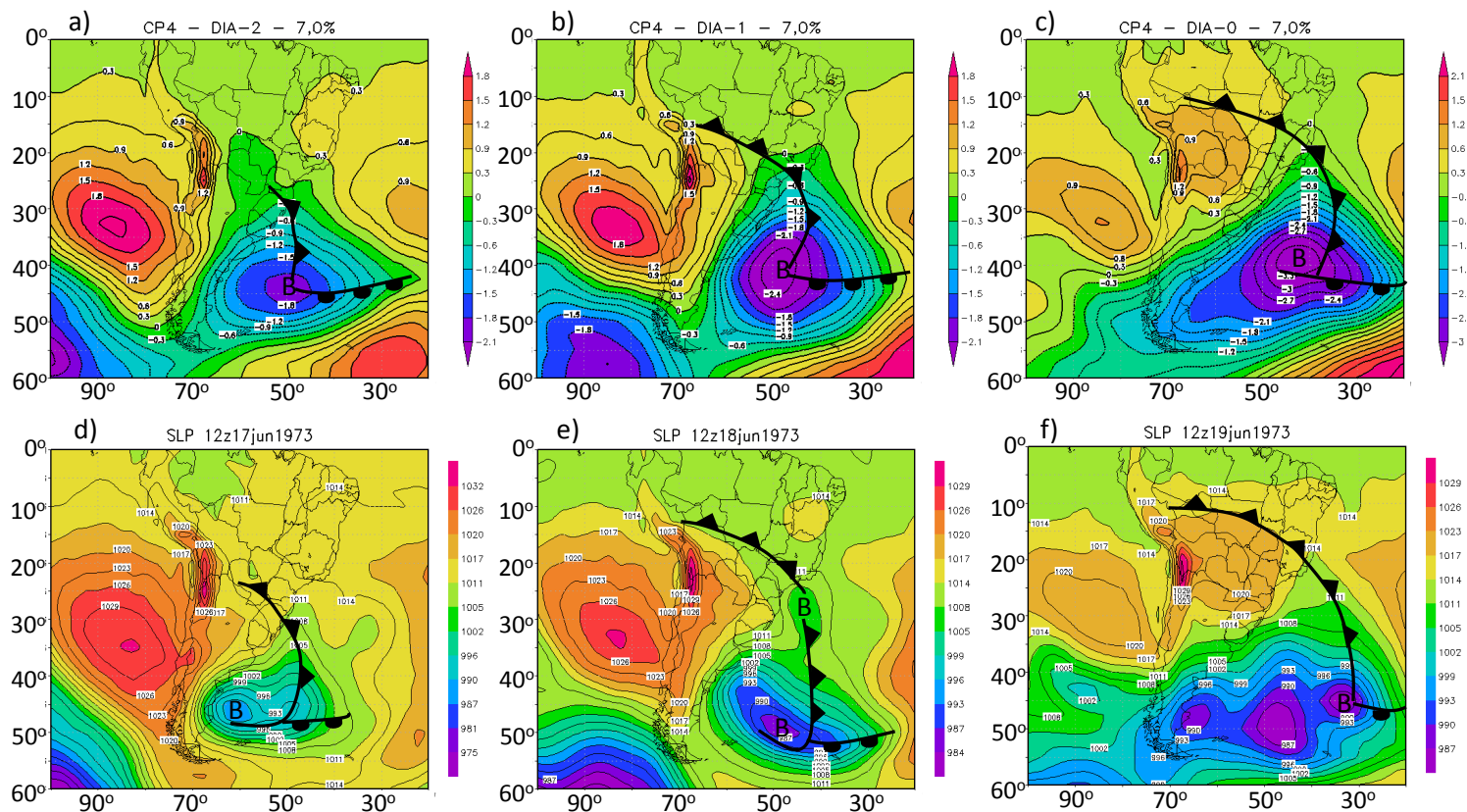

Figura 6 Similar à Figura 3, mas para o PSP4-Sup. O caso real de onda de frio se refere ao período de 17 a 19 de junho de 1973. 

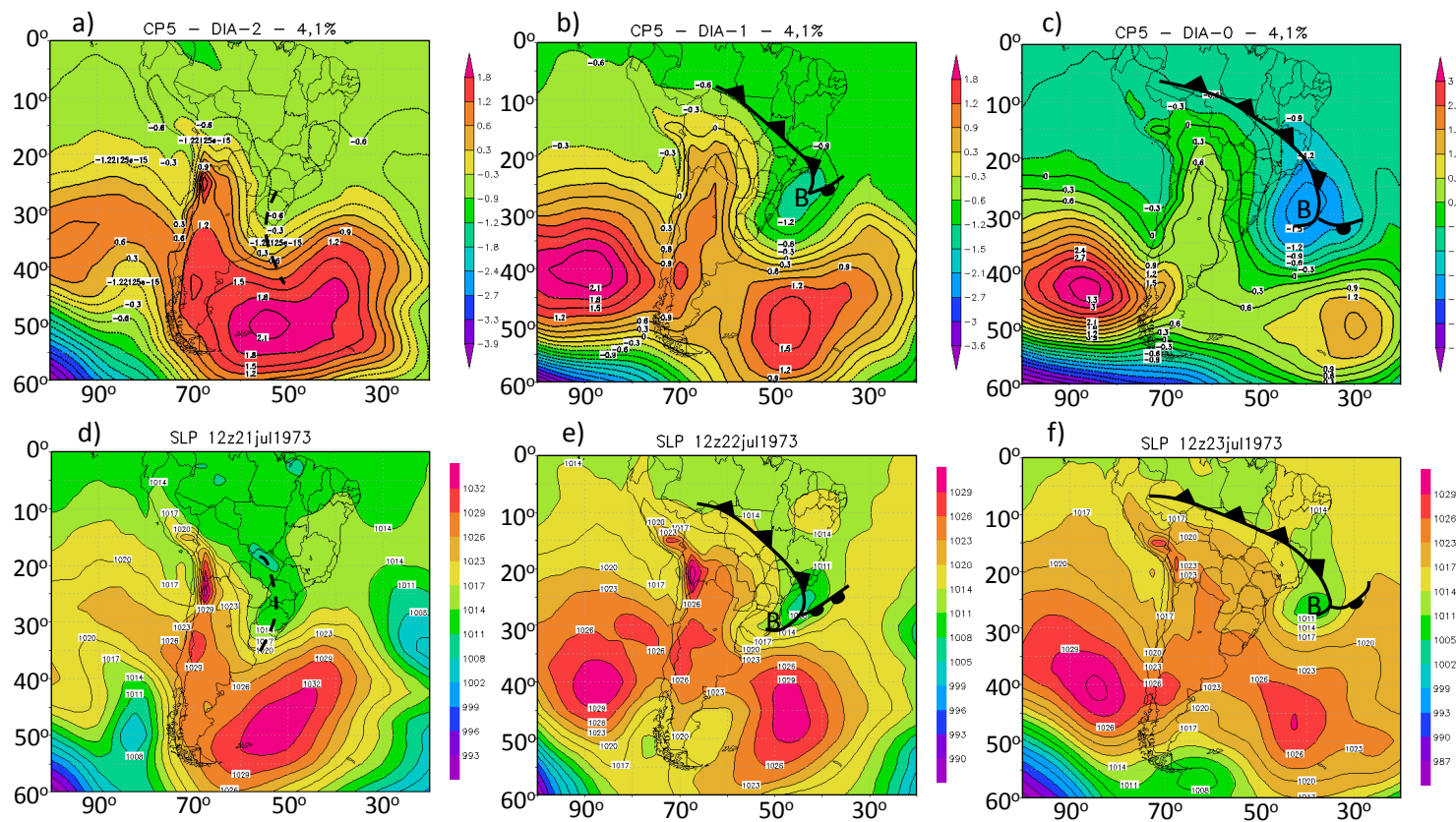

Figura 7 Similar à Figura 3, mas para o PSP5-Sup. O caso real de onda de frio se refere ao período de 21 a 23 de julho de 1973.

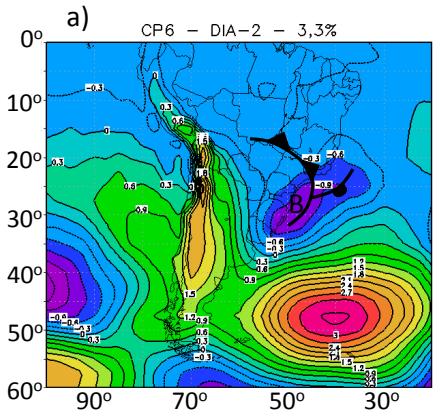

d) SLP 12z06jun 1997

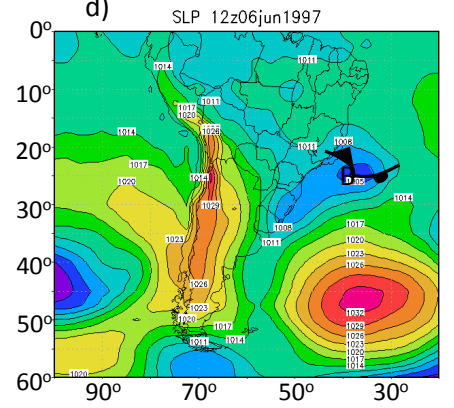

b)

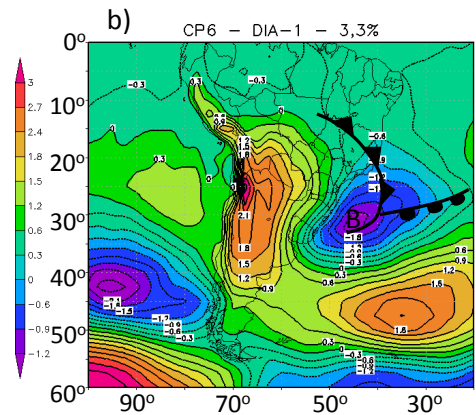

e) SLP 12z07jun1997

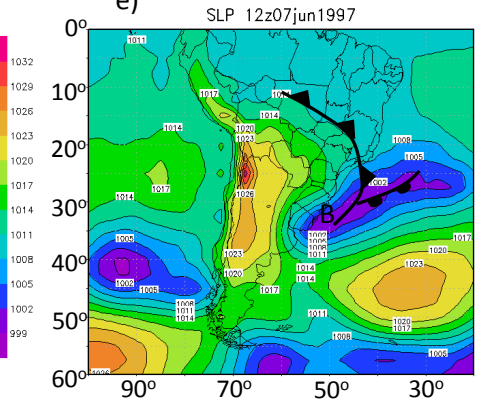

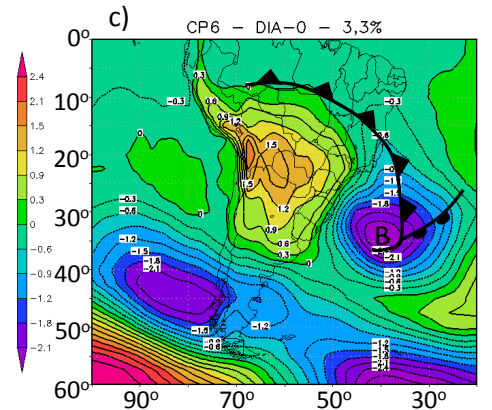

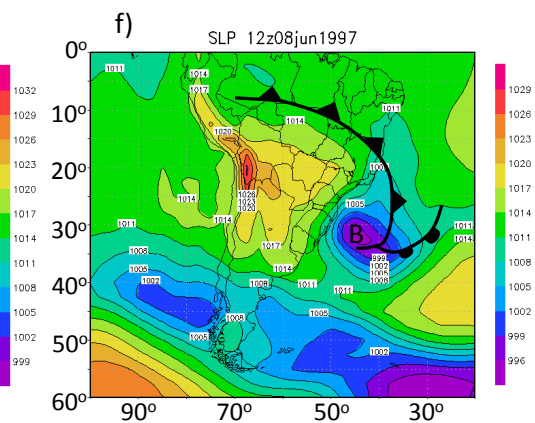

Figura 8 Similar à Figura 3, mas para o PSP6-Sup. O caso real de onda de frio se refere ao período de 06 a 08 de junho de 1997. 


\subsubsection{Altura Geopotencial em $500 \mathrm{hPa}$}

Como os sistemas atmosféricos em níveis médios da atmosfera, em geral, conduzem os sistemas meteorológicos em superfície, a análise dos PSPs também foi realizada para o nível de $500 \mathrm{hPa}$ a fim de fornecer subsídios para a discussão do acoplamento entre esses níveis da atmosfera na seção 3.2.3. Também é importante mencionar que o número de PSPs em $500 \mathrm{hPa}$ é menor do que o em superfície, pois quanto mais se afasta da superfície, mais suavizado é o escoamento atmosférico. Portanto, em $500 \mathrm{hPa}$ se consegue representar a variância total dos dados com um menor número de PSPs comparado à superfície.

Em 500 hPa, o primeiro PSP (PSP1-Alt, Figura 9a-c), que explica 42,5\% da variância dos dados, está associado a um padrão de onda com um cavado a cerca de $80^{\circ} \mathrm{W}$, uma crista em $\sim 50^{\circ} \mathrm{W}$ e um cavado a leste da crista (saindo do domínio analisado); sendo que os dois primeiros mostram centros de circulação fechada em seu interior. Embora esses sistemas apresentam pouco deslocamento para leste, a crista entre os dias -2 e 0 tem uma amplificação meridional, de modo que no dia 0 estende-se de $25^{\circ} \mathrm{S}$ a mais de $55^{\circ} \mathrm{S}$, no sentido noroeste-sudeste, da região sul do Brasil e Uruguai até o oceano Atlântico Sul (Figura 9c). Além disso, ao longo da sequência de dias, nota-se que a crista tende a "adentrar" o cavado localizado a seu lado leste. Com isso, o ar frio pode ficar aprisionado a norte da alta pressão e ocorrer uma situação de bloqueio atmosférico no oceano Atlântico. Esse PSP1-Alt foi identificado por Escobar (2007) como PSP3-Alt, no estudo das ondas de frio em São Paulo. O caso real altamente correlacionado $(0,91)$ com o PSP1-Alt corresponde aos dias 18 a 20 de julho de 2004 (Figura 9d-f). Nessa sequência é evidente o padrão de onda cavado-crista-cavado com a amplificação noroeste-sudeste da crista e sua atuação sobre o sul do Brasil. Embora o caso real (Figura 9d-f) seja bem correlacionado com o PSP1-Alt (Figura 9a-c), ele não mostra centros de circulação fechados. Como discutido em Escobar (2007), diferenças entre os PSPs e os casos observados podem ocorrer uma vez que os PSPs representam um modelo padrão de um grupo de várias situações reais, podendo algumas dessas se diferenciarem ligeiramente do padrão.

O segundo PSP (PSP2-Alt, Figura 10a-c), que explica 40,4\% da variância dos dados, está relacionado com dois centros de circulação fechada: sendo um de alta pressão localizado entre o oceano Pacífico e o sul da AS e o outro de baixa pressão localizado no oceano Atlântico. O vórtice ciclônico no Atlântico está associado a um cavado que se estende em direção ao norte da Argentina no dia -2 (Figura 10a) e atinge o sul de Mato Grosso do Sul no dia 0 (Figura 10c). Este sistema de baixa pressão de altitude reflete o deslocamento de um sistema frontal em superfície. Conforme o cavado frontal avança para nordeste, o anticiclone e sua crista associada penetram lentamente sobre o sul da AS. Ambos os sistemas (crista e cavado) determinam um escoamento predominantemente meridional de quadrante sul sobre o centro-sul do Brasil, conduzindo o anticiclone migratório de superfície até latitudes mais baixas. Desta maneira o ar frio com características polares consegue atingir a RSMG. Esse PSP2-Alt é similar ao obtido por Escobar (2007) no estudo de ondas de frio em 


\section{ISSN: 1980-055x (Impressa) 2237-8642 (Eletrônica)}

SP. O caso real altamente correlacionado $(0,90)$ com o PSP2-Alt refere-se aos dias 20 a 22 de julho de 1996 (Figura 10d-f). Esse caso mostra uma crista entre o oceano Pacífico e o sul da AS que se propaga lentamente para leste. No dia 0, a crista localiza-se entre o leste da Argentina e o oceano Atlântico, mas com menor amplitude do que nos dias anteriores.

O terceiro PSP (PSP3-Alt, Figura 11a-c), que explica 10,8\% da variância dos dados, está relacionado com um centro de circulação ciclônica embebido num cavado que se estende de forma meridional por todo o centro sul da AS. Infere-se que esse sistema de baixa pressão em altitude está associado com a presença de uma frente fria em superfície que é responsável pelo transporte de ar frio das mais altas para as mais baixas latitudes. Tal cavado é cercado tanto a oeste quanto a leste por centros de alta pressão. À medida que o cavado se desloca para leste ele se intensifica. No dia 0 (Figura 11c), esse sistema apresenta seu eixo sobre o centro-sul do Brasil. Tal PSP3-Alt é similar ao PSP2Alt obtido por Escobar (2007). O caso real altamente correlacionado $(0,67)$ com o PSP3-Alt corresponde ao período de 24 a 26 de junho de 1994 (Figura 11d-f). Esse mostra o domínio do cavado sobre o centro-sul da AS e intensificação do mesmo à medida que se desloca para leste.
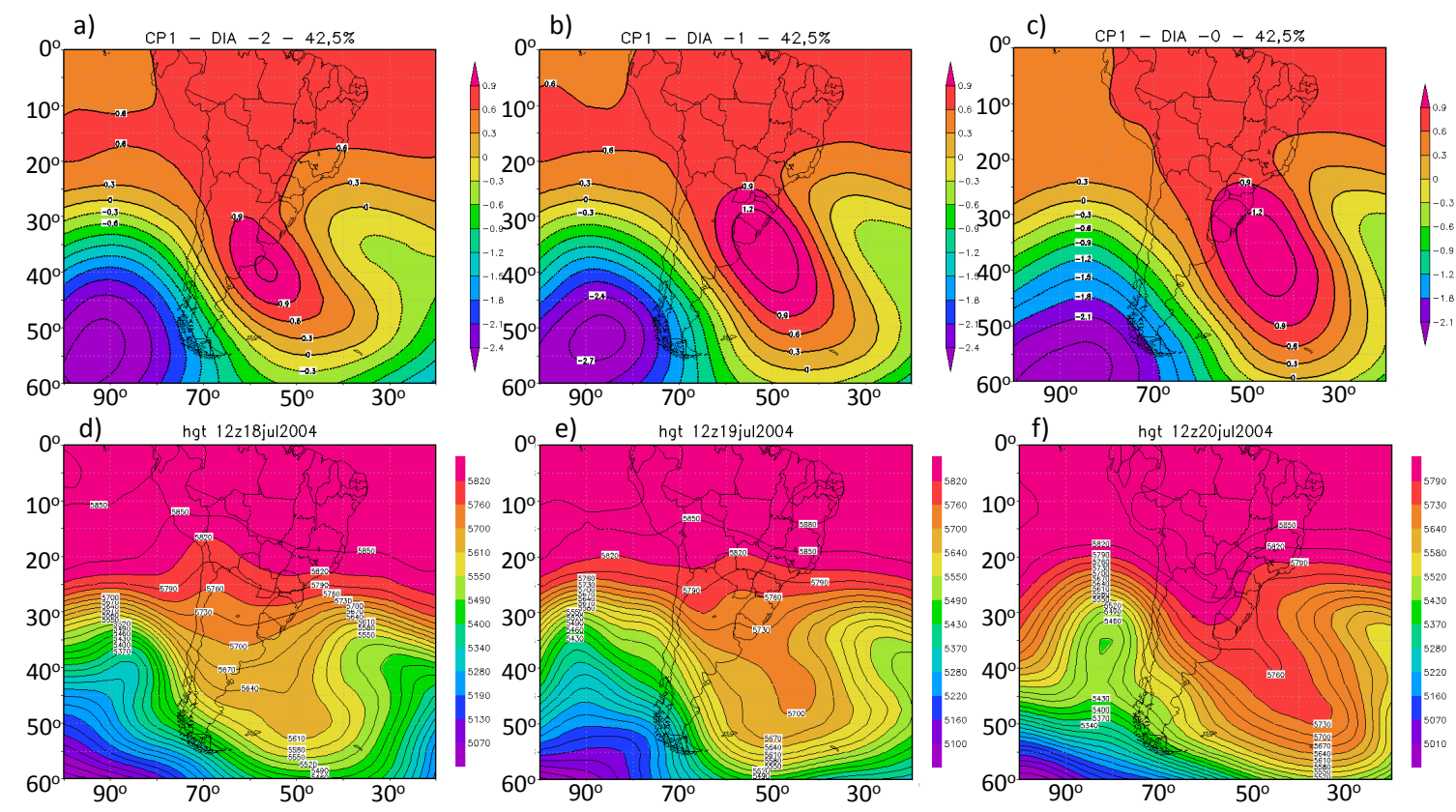

Figura 9 (a-c) Primeira Sequência de Componentes Principais (PSP1-Alt) para a altura geopotencial em $500 \mathrm{hPa}$ desde o dia -2 ao dia 0 e (d-f) caso real ocorrido entre 18 e 20 de julho de 2004 (altura geopotencial em metros). 


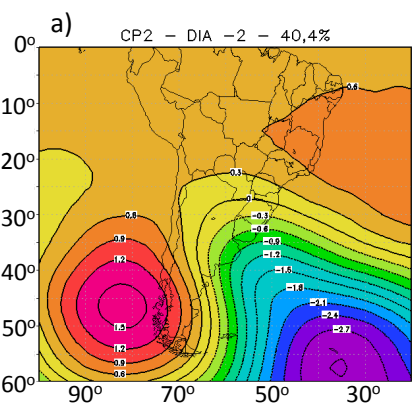

d)

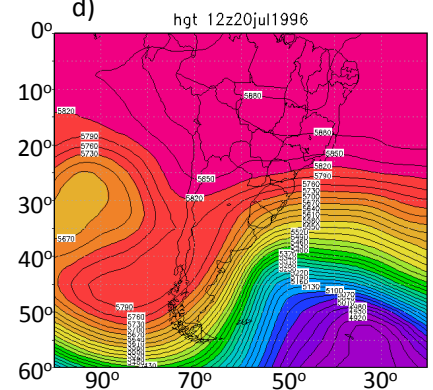

b)

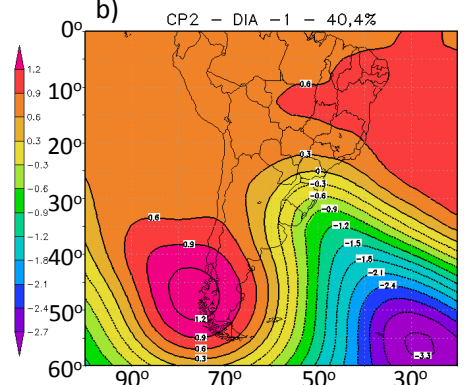

e)

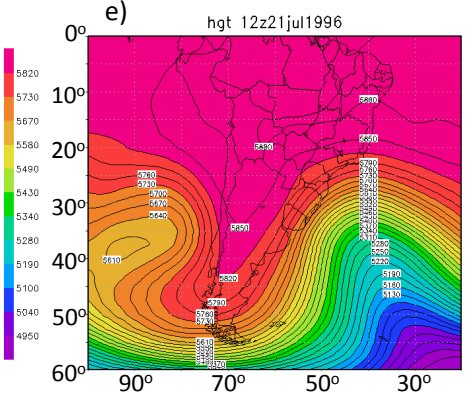

c)

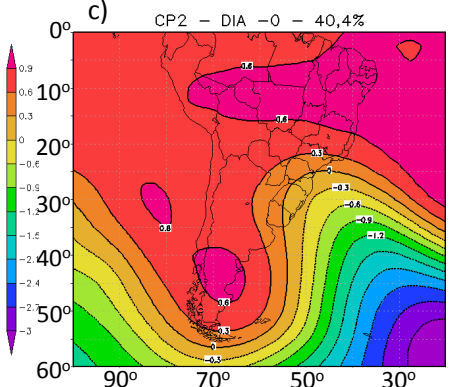

hgt $12 z 22$ jul1996

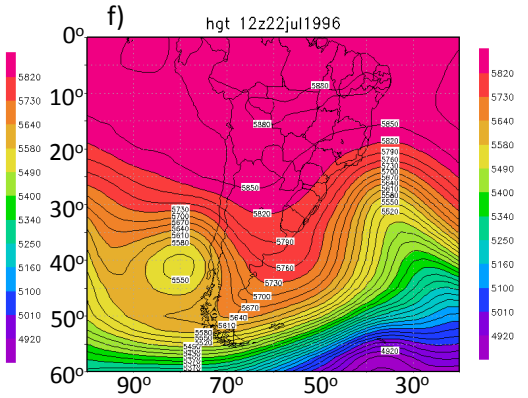

Figura 10 Similar à Figura 9, mas para o PSP2-Alt. O caso real se refere aos dias 20 a 22 de julho de 1996.
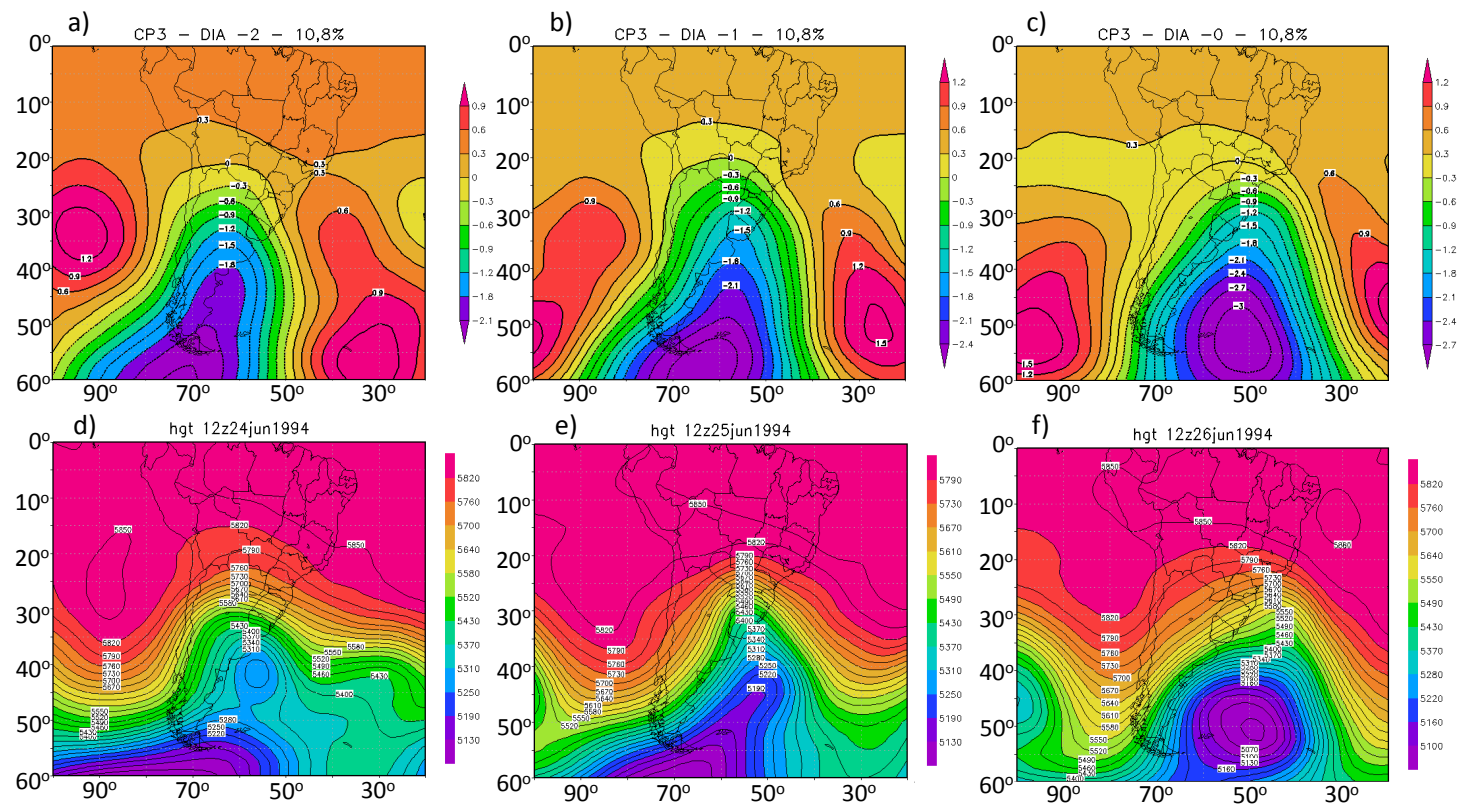

Figura 11 Similar à Figura 9, mas para o PSP3-Alt. O caso real se refere aos dias 24 a 26 de junho de 1994. 


\subsubsection{Acoplamento Superfície - Altitude}

Essa seção apresenta uma análise da estrutura vertical da circulação atmosférica quando da ocorrência de ondas de frio na RSMG. Para identificar o PSP-Sup relacionado ao PSP-Alt foi calculada a correlação entre as séries de factor loadings dos PSPs de ambos os níveis. Com isso, obteve-se que o PSP1Sup está bem correlacionado com o PSP2-Alt, o PSP2-Sup com o PSP1-Alt e o PSP3-Sup com o PSP3-Alt.

PSP1-Sup X PSP2-Alt: O modelo de circulação atmosférica representado pelo PSP1-Sup (Figura 3) e pelo PSP2-Alt (Figura 10) está associado às típicas incursões de ar frio na AS (ex. GARREAUD, 2000). Isto é, em superfície no dia -2 há um anticiclone pós-frontal no Pacífico, centrado em $45^{\circ} \mathrm{S}$ e $80^{\circ} \mathrm{W}$, que se desloca para leste e, no dia 0, domina o centro-sul da AS. A leste desse sistema há um intenso ciclone no Atlântico Sul e um ramo frontal frio sobre a AS.

Em 500 hPa há uma crista com um centro fechado de alta pressão e a leste, um intenso cavado com um vórtice ciclônico associado (Figura 10). Ambos os sistemas de altitude (crista e cavado) determinam um forte gradiente zonal de altura geopotencial que gera, em consequência, um intenso escoamento meridional de quadrante sul sobre grande parte do centro-sul de AS. Este padrão de circulação em altitude favorece o deslocamento meridional dos sistemas migratórios de superfície, permitindo que o ar frio atinja latitudes mais baixas. Em superfície pode-se observar também um forte gradiente zonal de pressão que favorece ventos de quadrante sul sobre parte da Argentina, Paraguai, Uruguai e o centro-sul do Brasil (Figura 3). Entre os dias -1 e 0, pode-se inferir que há forte advecção fria sobre parte do sul, sudeste e centro-oeste do Brasil, determinando a ocorrência de episódio de onda de frio na RSMG.

PSP2-Sup X PSP1-Alt: O modelo de circulação atmosférica representado pelo PSP2-Sup (Figura 4) e pelo PSP1-Alt (Figura 9) está relacionado a um sistema dinâmico com características barotrópicas. Considerando o nível de $500 \mathrm{hPa}$, observa-se (Figura 9a-c) uma crista com centro fechado de alta pressão se estendendo de noroeste a sudeste, entre o interior do continente e o oceano Atlântico Sul. A leste deste sistema de alta pressão há um cavado cujo eixo se estende também de noroeste a sudeste. Ao longo de toda a sequência, a crista se amplifica e o cavado se inclina em direção ao sudeste do Brasil. Em consequência, ocorre um lento deslocamento para leste de ambos os sistemas.

Em superfície (Figura 4a-c) se observa um reflexo do padrão descrito em altitude: uma frente fria no sudeste e a oeste dela um intenso e abrangente anticiclone que cobre grande parte do centro-sul da AS. É possível observar também que ambos os sistemas em superfície (anticiclone e sistema frontal) encontram-se praticamente em fase com os sistemas de altitude, caracterizando em consequência um sistema atmosférico com estrutura dinâmica barotrópica.

Considerando novamente o nível de 500 hPa (Figura 9), à medida que a crista se inclina no sentido noroeste-sudeste, ela tende a adentrar o cavado. 
Com esse processo, em geral, há aprisionamento de ar frio no centro do cavado e a possível formação de um vórtice ciclônico de altos níveis (ou cutoff low em inglês). Esse processo é descrito na literatura como quebra da onda de Rossby (POSTEL e HICHMAN, 1999). O vórtice ciclônico em $500 \mathrm{hPa}$ pode favorecer o desenvolvimento da baixa em superfície, através de um processo ciclogenético. Portanto, os sistemas em superfície (Figura 4) vão seguir a configuração dos sistemas em $500 \mathrm{hPa}$ (Figura 9), onde o ciclone fica aparentemente cercado pelo sistema de alta pressão que se localiza praticamente sob a crista em $500 \mathrm{hPa}$. Cabe ressaltar que os ciclones cercados por alta pressão possuem deslocamento lento e quando ocorridos próximos ao continente podem impactá-lo com condições de mal tempo. Um exemplo é o ciclone que ocorreu na primeira semana de maio de 2008 descrito em Reboita et al. (2009). Na relação do PSP2Sup e PSP1-Alt, as ondas de frio na RSMG estão mais associadas com o processo de resfriamento radiativo noturno pela semi-estacionariedade do anticiclone sobre a região em estudo do que pela a advecção de ar frio.

PSP3-Sup X PSP3-Alt: O PSP3-Sup (Figura 5) está relacionado com o PSP3-Alt (Figura 11) e ambos indicam o padrão climatológico de inverno na AS, onde em superfície (Figura 5) há um cavado que se estende do extremo sul da AS e se conecta com a BNOA e a leste dele há a atuação do setor oeste-noroeste do ASAS sobre parte das regiões sul e sudeste do Brasil. Esses sistemas de superfície estão acoplados baroclinicamente com um cavado e uma crista, respectivamente, em $500 \mathrm{hPa}$. Na situação descrita, a ocorrência de ondas de frio na RSMG deve-se à perda radiativa noturna pelas condições de tempo bom causadas pela semi-estacionariedade do ASAS.

\section{CONCLUSÃO}

Esse estudo utilizou dados de temperatura mínima e máxima medidos na estação meteorológica de Lavras, entre 1965 a 2014, para representar a RSMG. Com tais dados, computaram-se a temperatura média diária e o percentil de $5 \%$ dessa variável considerando os meses de maio a setembro a fim de identificar os eventos de ondas de frio. Em média, há cerca de 1,8 eventos por ano e com duração média de 3 dias. Entretanto, há uma grande variabilidade anual na ocorrência das ondas de frio: enquanto em 1968 foram identificados 8 casos em 2014, por exemplo, não houve nenhum registro.

A fim de caracterizar os padrões sinóticos de superfície e altitude associados à ocorrência de ondas de frio, foram utilizados dados de PNMM e de altura geopotencial em $500 \mathrm{hPa}$ (da reanálise R1) juntamente com a técnica de Padrões de Sequências Principais (PSPs). Em superfície, 6 PSPs representaram a maior parte da variância dos dados, enquanto em $500 \mathrm{hPa}, 3 \mathrm{PSPs}$. Como o escoamento em níveis mais afastados da superfície é mais suavizado, há um menor número de PSPs que explicam a variabilidade dos dados.

Os PSPs revelaram que os episódios de ondas de frio na RSMG estão associados principalmente com: advecção de ar frio (PSPs-Sup 1, 4, 5 e 6) e resfriamento radiativo noturno da superfície (PSPs-Sup 2 e 3). Os PSPs-Sup 1 e 4 estão associados com sistemas frontais, cujo ar frio com características polar é advectado do sul da AS. Já, os PSPs-Sup 5 e 6 estão associados com episódios 
ciclogenéticos gerados no oceano Atlântico Sudoeste, a leste da região sulsudeste do Brasil. Esses dois últimos padrões é um dos diferenciais do presente estudo em relação aos trabalhos prévios sobre ondas de frio.

O PSP1-Sup e seu correspondente PSP2-Alt e o PSP2-Sup e o seu correspondente PSP1-Alt são os padrões mais típicos quando da ocorrência de ondas de frio na RSMG. O PSP1-Sup mostrou que as incursões de ar frio na AS, associadas à presença de um anticiclone pós-frontal entre o oceano Pacífico e sul da AS e um ciclone em latitudes médias no oceano Atlântico, são importantes no processo de advecção de ar frio originando as ondas de frio na RSMG. Esse padrão em superfície está associado com uma crista em $500 \mathrm{hPa}$, entre o oceano Pacífico e o sul da AS, e um cavado frontal bem amplificado no oceano Atlântico com orientação noroeste/sudeste que chega atingir a região sul do Brasil. Este padrão sinótico de superfície e altitude está associado com as típicas incursões de ar frio na AS descritas por Girardi (1983), Garreaud (2000) e Escobar (2007).

Já o PSP2-Sup mostrou que um anticiclone pós-frontal adquire características subtropicais e acaba permanecendo sobre a RSMG favorecendo a redução das temperaturas com o passar dos dias, principalmente por efeito da perda noturna de radiação. A configuração do anticiclone está relacionada com o padrão dos sistemas atmosféricos em $500 \mathrm{hPa}$ (PSP1-Alt) em que há a amplificação meridional de uma crista (com centro em $40^{\circ} \mathrm{S}$ e $55^{\circ} \mathrm{W}$ ) de forma que essa adentra o setor sudoeste do cavado localizado no oceano Atlântico. Com esse processo, pode ocorrer aprisionamento de ar frio no centro do cavado e a possível formação de um vórtice ciclônico de altos níveis. Com relação ao PSP3-Sup e o seu correspondente PSP3-Alt, esses são padrões associados com a circulação média da atmosfera que está caracterizada pela BNOA e pelo ASAS (ESCOBAR e SELUCHI, 2012). Durante o inverno a borda ocidental do ASAS encontra-se mais a oeste em relação ao verão (REBOITA et al., 2012), favorecendo a perda noturna de radiação.

Por fim, destaca-se que esse estudo pode servir como guia objetivo na prática operacional de previsão do tempo para prognóstico da ocorrência de ondas de frio na RSMG.

AGRADECIMENTOS: Os autores agradecem ao NCEP/NCAR, INMET e USGS pelos dados utilizados no presente estudo. Além disso, agradecem ao mestrando Marcelo Rodrigues, da Universidade Federal de Itajubá, pela elaboração da Figura 1 - área de estudo e topografia da América do Sul.

\section{REFERÊNCIAS BIBLIOGRÁFICAS}

CATTELL, R. The scientific use of factor analysis: in Behavioral and Life Sciences. Plenum Press. New York and London, 1978.

COMPAGNUCCI, R. H.; ARANEO, D.; CANZIANI, P. O. Principal sequence pattern analysis: a new approach to classifying the evolution of atmospheric systems. International Journal of Climatology, v. 21, p. 197-217, 2001. 
ESCOBAR, G. C. J. Padrões sinóticos associados a ondas de frio na cidade de São Paulo. Revista Brasileira de Meteorologia, v. 22, p. 241-254, 2007.

ESCOBAR, G. C. J.; SELUCHI, M. E. Classificação sinótica dos campos de pressão atmosférica na América do Sul e sua relação com as baixas do Chaco e do Noroeste argentino. Revista Brasileira de Meteorologia, v. 27, p. 365-375, 2012.

FORTUNE, M. A.; KOUSKY, V. E. Two Severe Freezes in Brazil: Precursors and Synoptic Evolution. Monthly Weather Review, v. 191, p. 181-196, 1983.

GARREAUD, R. D. Cold Air Incursions over Subtropical South America: Mean Structure and Dynamics. Monthly Weather Review, v. 128, p. 2544-2559, 2000.

GIRARDI, C. O Poço dos Andes. Relatório Técnico ECA 01/83, Centro Técnico Aeroespacial, 1983.

GREEN, P. Analysing Multivariate Data. The Dryden Press. Illinois, U.S.A, $519,1978$.

HAMILTON, M.; TARIFA J. Synoptic aspects of a polar outbreak leading to frost in tropical Brazil, July 1972. Monthly Weather Review, v. 106, p. 1545-1556, 1978.

HARMAN, H. Modern Factor Analysis. The University of Chicago Press Chicago, IL, 1976.

KALNAY, E., et al. NCEP/NCAR 40-year Reanalysis Project. Bull. Am. Meteorol. Soc., v. 77, p. 437-471, 1996.

LUPO, A. R.; NOCERA, J. J.; BOSART, L. F. South American cold surges: types, composites, and cases stydies. Monthly Weather Review, v. 129, n. 5, p. 1021-1041, 2001.

MARENGO, J.; CORNEJO, A.; SATYAMURTY, P.; NOBRE, C. Cold surges in tropical and extratropical South America: The Strong Event in June 1994. Monthly Weather Review, v. 125, n. 11, p. 2759-2786, 1997.

NAIRN, J.; FAWCETT, R. Defining heatwaves: heatwave defined as a heat impact event servicing all community and business sectors in Australia. CAWCR Technical Report Nº. 060, 2013.

PEZZA, A. B.; AMBRIZZI, T. Cold waves in South America and freezing temperatures in São Paulo: histórical background (1988-2003) and case studies of cyclone and anticyclone tracks. Revista Brasileira de Meteorologia, v. 20, n. 1, p. 141- 158, 2005. 
POSTEL, G. A.; HITCHMAN, M. H. Climatology of Rossby wave breaking along the subtropical tropopause. J. Atmos. Sci.,v. 56, p. 359-373, 1999.

REBOITA, M. S.; IWABE. C. M. N.; DA ROCHA, R. P.; AMBRIZZI, T. Análise de um ciclone semi-estacionário na costa sul do Brasil associado a bloqueio atmosférico. Revista Brasileira de Meteorologia, v. 24, n. 4, p. 407 - 422, 2009.

REBOITA, M. S.; KRUSCHE, N.; AMBRIZZI, T.; DA ROCHA, R. P. Entendendo o Tempo e o Clima na América do Sul. Terra E Didática, v. 8, n. 1, p. 34-50, 2012.

RICHMAN, M. Rotation of Principal Components. Journal of Climatology, v. 6, n. 3, p. 293-335, 1986.

RICHMAN, M.; ANGEL, J.; GONG, X. Determination of Dimensionality in Eingenanalysis. In: V International Meeting on Statistical Climatology, v. 6, Canadá. Anais: 1992. p. 229-235, 1992.

SATYAMURTY, P.; FONSECA, J. F. B.; BOTTINO, M. J.; SELUCHI, M. E.; LOURENÇO, M. C. M.; GONÇALVES, L. G. G. An early freeze in southern Brazil in April 1999 and its NWP guidance. Meteorological Applications, v. 9, p. 113$128,2002$.

SPRENGER, M.; MARTIUS, O.; ARNOLD, J. Cold surge episodes over southeastern Brazil - a potencial vorticity perspective. International Journal of Climatology, v. 33, p. 2758-2767, 2013.

SUGAHARA, S.; ROCHA, R. P.; YNOUE, R. Y.; SILVEIRA, R. B. Homogeneity assessment of a station climate series (1933-2005) in the Metropolitan Area of São Paulo: instruments change and urbanization effects. Theoretical and Applied Climatology, v. 107, n. 3-4, p. 361-374, 2012.

VERA, C. S.; VIGLIAROLO, P. K. A Diagnostic Study of Cold - Air Outbreaks over South America. Monthly Weather Review, v. 128, p. 3 - 24, 2000.

WILKS, D. Statistical Methods in the Atmospheric Sciences. 2nd. ed. Academic Press, 2006. 